Platinum-golds are renowned for their exccllent soldering properties and they exhibit a widle compatibility with tlickfilm resistors. A resistor array is shown which uges a platinum-gold conductor for the interconnection of resistors and solder attachment of wires

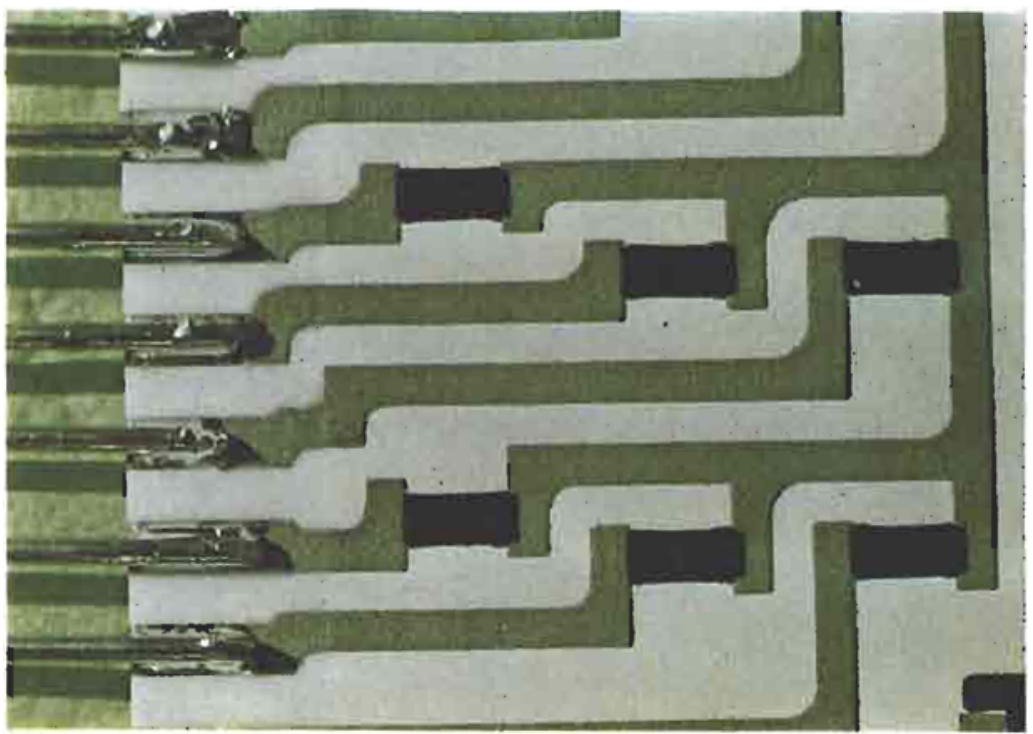

including palladium-silvers. The chicf disadvantage of platinum-golds is that they are sometimes more expensive than golds. Leach resistance of platinumgold is considerably better than that of palladiumgolds, and resistor compatibility is on a par with that shown by gold terminations. Otherwise the properties of platinum-golds closely resemble those of palladiumgolds including loss in strength of solder connections on ageing. Intermetallic compound formation is held responsible for much of the loss in strength, but this time the intermetallic is thought to be based on gold and tin.

\section{Ternary Noble Metal Conductors}

Several pastes are available claiming the use of three noble metal components instead of two metals. The pastes are basically platinum-golds or palladiumgolds where partial substitution of silver has been made for gold, or where mixtures of platinum and palladium with gold have been preferred. Properties are closely allied with their parent compositions.

\section{Summary}

Gold is an essential ingredient of thick-film conductors for applications requiring high performance and the integration of various components by wire, beam lead, or eutectic die bonding. Incorporation of a second component in gold films as exemplified by palladium-golds and platinum-golds improves the flexibility of conductors by allowing solder connections to be made. Moreover, platinum-gold offers the best soldering performance of any thick-film conductor. Although new materials, including base metals, may eventually gain a foothold in some applications, conductors using gold should continue to be used extensively for many more years.

\title{
A Guide to Commercially Available Thick-Film Materials
}

Thick-Film Conductor Survey: ERA Report 75-43

A very large number of thick-film conductor preparations is now available to the user, new and modified pastes having been introduced by a growing number of suppliers. These have made possible significant improvements in the quality of the end product and in its performance, but it has not always been possible to identify the advantages of improved adhesion, the virtues of alternative alloy compositions, better printing capability, and the introduction of reactive bonding.

To meet the need for a comprehensive guide to the thick-film conductors that are available commercially on a world-wide basis, this survey has been prepared to provide an objective and up-todate guide in one convenient volume.
The report opens with a concise account of the general principles underlying the selection of ingredients of pastes and of the compromises that have to be made to secure the desired characteristics. The properties of eight distinct groups of conductors are discussed, and the relative merits and disadvantages of each are summarised. Some 300 conductor pastes made by twelve manufacturers are listed under alloy-type headings, and the properties of each are set out in tabular form in terms of resistivity, solderability, leach resistance, adhesion, wire and die-bonding characteristics, printing capability, and compatibility with other materials.

The report, running to 196 pages, is available at $£ 45$ from ERA (formerly the Electrical Research Association), Leatherhead, Surrey, England. 